\title{
Reservoir water intake pump house location optimization on water age
}

\author{
YANG Jinyan ${ }^{1, a}$, XU Yong ${ }^{1}$, ZHOU Jie ${ }^{2,3}$ and WU Shiqiang ${ }^{2,3}$ \\ ${ }^{1}$ Jiangsu province hydrology and water resource investigation bureau Suzhou sub bureau, Suzhou 215129, China \\ ${ }^{2}$ Nanjing hydraulic research institute, Nanjing 210029, China \\ ${ }^{3}$ State key laboratory of hydrology-water resources and hydraulic engineering, Nanjing 210024, China
}

\begin{abstract}
Reservoir circulating currents and water age is considered to optimize the intake pump house locations. Since the air temperature, water depth and nitrogen and phosphor input is hard to control, to optimize the water age and cycling currents of reservoir by water intake pump house location optimization is one of the most usefully way to control the risk of eutrophication of reservoir by growth inhibition of age.
\end{abstract}

\section{INTRODUCTION}

In recent years, the eutrophication of reservoir water bodies in China has become increasingly serious, and its pollution sources are extremely complicated. The potential hazard is very severe, which has become one of the most prominent environmental problems in water environmental protection. According to surveys conducted in recent years in China, some large and medium-sized reservoirs are in an excessive state of moderate eutrophication to eutrophication. How to control the eutrophication of water bodies has become an urgent problem to be solved by the reservoir operation management unit.

In addition to reducing the input of nitrogen and phosphorus nutrients, the introduction of biological control algae, and ecological floating islands, the eutrophication control of reservoirs is also a very important measure to shorten the water exchange period of reservoirs ${ }^{[1]}$.

There are two water plants and two salt-avoiding storing reservoirs in Taicang City. The water plant is the second water plant (hereinafter referred to as the 2nd water plant) and the third water plant (hereinafter referred to as the 3rd water plant). The reservoir is the Langang Reservoir and the Liu River Reservoir. The 3rd water plant is located $16 \mathrm{~km}$ southeast of the $2 \mathrm{nd}$ water plant. The water source is located at the Liu River Reservoir in the upper reaches of the Liu River estuary of the Yangtze River. The situation on site is shown in Figure 1. The reservoir has a total storage capacity of 17.42 million cubic meters, an effective storage capacity of 14.27 million cubic meters, an emergency storage capacity of 2.42 million cubic meters, and a dead storage capacity of 3.15 million cubic meters. The highest water level is $5.5 \mathrm{~m}$, the dead water level is $-1.2 \mathrm{~m}$, the emergency water level is $0.0 \mathrm{~m}$, the summer running water level is $0.0 \sim 1.5 \mathrm{~m}$, the reservoir bottom level is -
$2.80 \mathrm{~m}$, and the water surface area is 2.2 million $\mathrm{m} 2$. The 3rd water plant adopts the method of salt-avoiding and freshwater reservoir. Its longest time to deal with the period of Yangtze River estuary not suitable for taking water are 25 days. The first-stage project design has a daily water supply capacity of 400,000 square meters and a long-term planning and construction of 600,000 square meters.

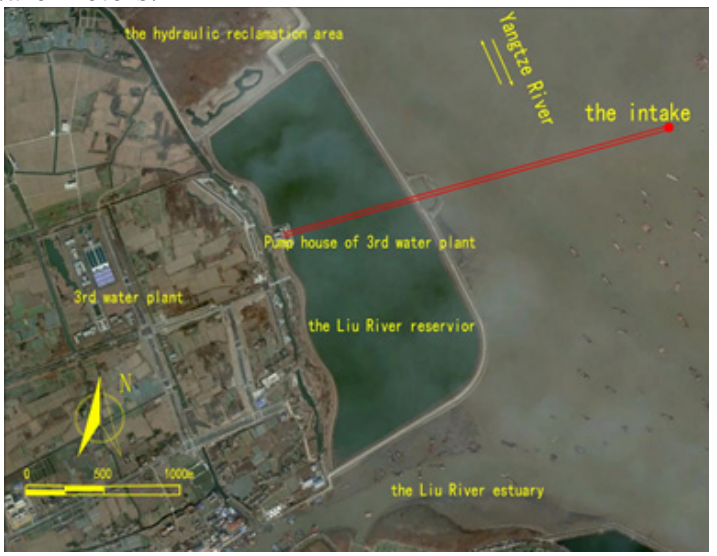

Fig. 1 current layout of The Liu River reservoir

The Liu River Water Source Project started construction in October 2010 and was put into operation on September 25, 2013. In the two years since the operation of the reservoir, the actual daily water supply was less than 200,000 square meters, and the gap between the design and water supply capacity was large. In order to shorten the water exchange cycle, the Taicang 3rd water plant reduced the average water level to about $1.0 \mathrm{~m}$, corresponding to a storage capacity of about 7.6 million cubic meters, and the water exchange period was about 38 days. Due to the long water exchange period, the eutrophication degree of the reservoir water is intensified during the high temperature in summer, and the highest number of algal cells measured by the water plant reaches 5.14 million/L.

\footnotetext{
a Corresponding author: Yang Jinyan (1977-), female, Jiangsu Qidong, senior engineer, master, mainly engaged in the direction of hydrology and water resources. E-mail:184459173@qq.com
} 
The water source of the 2 nd water plant is planned to be relocated to the reservoir, which can improve the utilization rate of the raw water of the reservoir, reduce the operation and management costs, and shorten the water exchange period of the reservoir. It can not only reduce the investment in redundant construction, but also help control the eutrophication of the reservoir. The actual daily water supply of the 2nd water plant is 200,000 square meters. According to the current operation and management mode of the reservoir, the water exchange cycle will be shortened to about 15 days according to the actual water supply.

Due to the large storage capacity and small water consumption, the Liu River Reservoir has caused the fluidity of the reservoir raw water to be low, and the water depth is shallow, and the algae in the reservoir breed. By constructing the Liu River water intake and water pumping station of the 2 nd water plant, it can form a multi-point water intake and uniform water exchange pattern with the existing Liu River pumping station of 3rd water plant, effectively improve the fluidity of the reservoir raw water, and improve the raw water quality to a certain extent. At the same time, the water intake and water pumping station of the project also has the function of changing water. When the Liu River reservoir needs to change water to improve water quality, the raw water of the reservoir can be discharged to the Yangtze River to improve the raw water quality of the Liu River Reservoir. In order to better scientifically arrange the location of the water pumping house and the water intake head of the 2 nd water plant, it is necessary to make full use of the circulation generated by the water to improve the flow characteristics of the reservoir area, effectively control the eutrophication of the water body, and optimize the water intake plan.

\section{COMPARISON METHOD}

Reservoir water flow is often affected by factors such as wind shear stress, thermal buoyancy, and water withdrawal (source, sink). Because the water depth of the reservoir where the project is located is shallow, the water depth is only $8 \mathrm{~m}$ at the highest water level, and the average water storage depth in summer is only $4 \mathrm{~m}$, so the thermal buoyancy has little effect. Due to the large area of the reservoir, reaching 2.2 million square meters. The main factor affecting the water flow is wind, followed by the sink formed by the water. Because the shallow stream lakes will generate circulation in the lake plane and the vertical plane, the surface water flow direction is opposite to the bottom water flow direction. Therefore, the simulation of wind flow generation should be carried out by layered three-dimensional model. The mathematical model adopts the EFDC model developed by the US Environmental Protection Agency(EPA). The model is applicable to a wide range of applications. The simulation of the three-dimensional flow simulation of the lake library is high. The water body water exchange period is simulated several times ${ }^{[2-3]}$. The calculation of the water body age is described in this research ${ }^{[4]}$.
The shape of the Liu River Reservoir is basically ruled. The entire reservoir is divided into square grids of $20 \mathrm{~m} \times 20 \mathrm{~m}$, and a total of 5,504 grid units are arranged. The calculation is divided into 6 layers, each layer being equal in thickness. The calculation time step is $10 \mathrm{~s}$. The topography of the reservoir adopts the elevation after dredging, which is basically $-2.80 \mathrm{~m}$. The initial water level is calculated using the average summer operating water level of $1.0 \mathrm{~m}$.

The roughness of the bottom of the reservoir is the same as the average roughness 0.016 of the Yangtze River estuary. Since the flow velocity in the reservoir is very small, the parameter is not sensitive, so the parameter of the model no longer determines.

The wind speed is calculated as the average wind speed of Taicang $3.6 \mathrm{~m} / \mathrm{s}$, and the wind direction is SSE and SE.

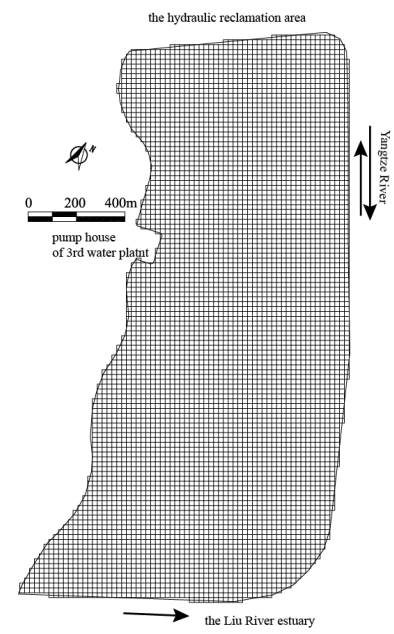

Fig. 2 grid layout diagram

\section{OPTIONAL PLAN}

The pumping station of this project should use the raw water of Liu River reservoir, so it should be close to the site of Liu River reservoir. Liu River reservoir is located on the southeast side of Taicang City, bordering Shanghai, with the Yangtze River on the east, Liu River estuary on the south, a landscape park on the west and a water source protection and isolation zone on the north. As the current 3rd water plant pumping station is located in the middle of the west side of the Liu River, there are three main options for the site selection of the new pumping station. The pumping station is located at the northeast, southwest and northwest corners of the Liu River Reservoir.

For the above three plans, the EFDC model developed by the US Environmental Protection Agency was used to simulate the influence of water abstraction from the 2 nd water plant on the water flow structure in the reservoir area. Since the current water supply operation status of the 2nd water plant is basically maintained at 200,000 tons per day, for the sake of safety considerations, this report uses the water intake flow rate of 200,000 tons/day. 


\section{RESERVOIR FLOW FIELD SIMULATION}

According to the calculation, the average streamline diagram of the vertical line of the first, second and third reservoir areas of the 2nd water plant pumping station in the first, second and third reservoir areas of the 2nd water plant pumping station is shown in Figure 3 under the action of the southeast wind with a wind speed of $3.6 \mathrm{~m} / \mathrm{s}$ at a height of $10 \mathrm{~m}$.
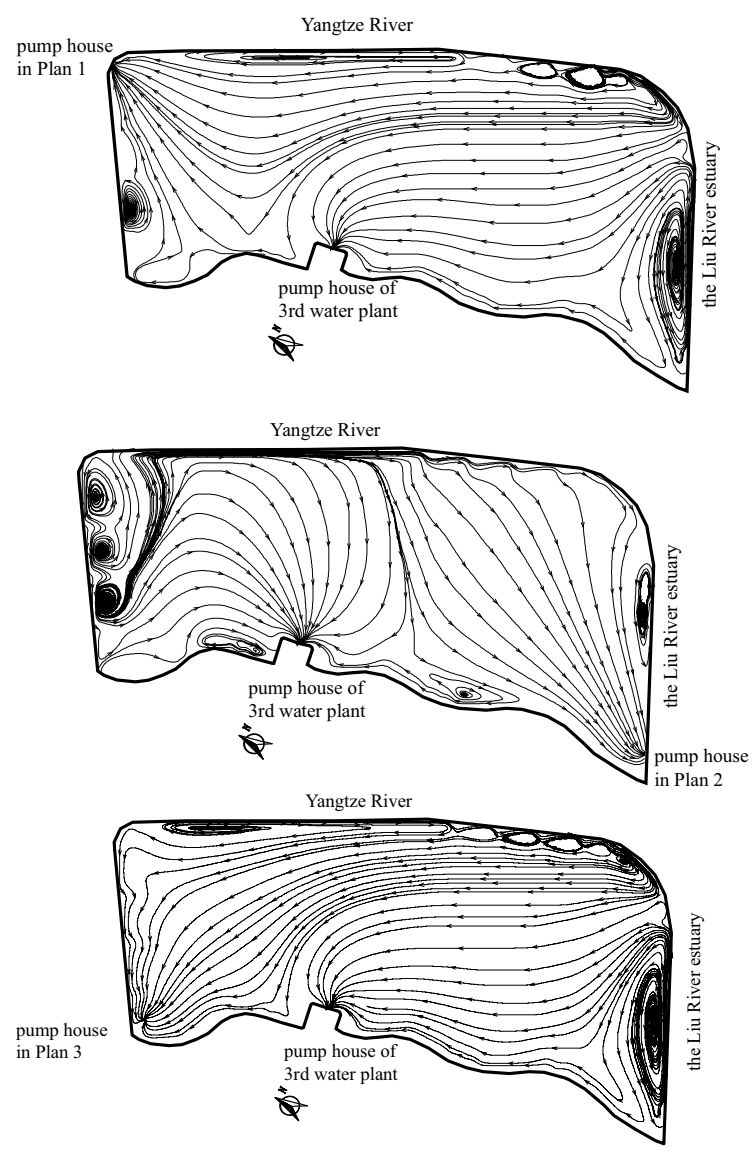

Fig. 3 Average vertical flow field of each scheme during reservoir water supply

The above calculation results show that:

(1) When the 2nd water plant and the 3rd water plant are simultaneously supplied with water, the layout plan 1 is adopted. The water intake of the 2 nd water plant mainly comes from the water in the northeast corner and the eastern half of the reservoir. The water intake of the 3rd water plant mainly comes from the southwest corner and the western half of the reservoir. When using the layout plan 2, the water intake of the 2 nd water plant mainly comes from the water in the south reservoir area of the pump house of 3rd water plant. The water intake of the 3rd water plant mainly comes from the water in the reservoir area north of the pump house of 3rd water Plant; When the layout plan 3 is adopted, the water source location of the 2 nd water plant and the 3 rd water plant is basically the same as that of the plan 1 .

(2) When the Yangtze River replenishes the reservoir, the layout plan 1 and the plan 3: The water from the 2nd water plant will soon be able to obtain the Yangtze River water newly replenished into the reservoir, and the layout plan will require 2 days of new Yangtze River water. When the water supply area is reached, only one day of new Yangtze River water can be added to the water intake area when the plan 3 is used. When the layout plan 2 is used, the newly supplemented Yangtze River water cannot reach the water intake of the 2nd water plant within 5 days of hydration. The water intake of the 2nd water plant is the water body after the supplementary water is fully mixed in the reservoir.

(3) When adopting the layout plan 2, the water intake of the 2nd water plant will not affect the overall trend of the surface water body flowing from south to north under the summer southeast wind stress. Once the reservoir algae breeds, the algae in the surface water will not drift. Go to the location of the pump house in the plan 2; when the layout plan 3 is adopted, the water intake position of the 2nd water plant is the lower air outlet. When the algae grow in the reservoir, the algae in the surface water will drift to the position of the pumping house.

In summary, when the layout plan 1 and plan 3 are adopted, the water intake water of the 2 nd water plant is in the downwind of the southeast wind, and the algae in the upper water body easily drifts to the water intake water with the water flow. The water intake of the 2 nd water plant mainly comes from the water in the northeast corner of the reservoir area and the reservoir in the eastern half. This part of the water body is basically the newly added Yangtze River water, and the water intake of the 3rd water plant mainly comes from the water body of the western half of the reservoir near the pump house. The water in the southwest corner is difficult to get a mix of newly replenished Yangtze River water, causing a large amount of new water to be removed and a large amount of old water not being blended with new water. The advantage of these two plans is that when the algae disaster occurs in the head of the water intake of the 2nd water plant, the Yangtze River water is immediately replenished. The Yangtze River water only needs to arrive at the water intake area of the 2 nd water plant after 2 days; when the layout plan 2 is used, the water from the 2 nd water plant is taken. Mainly from the water in the south reservoir area of the pump house of the 2nd water plant. The water from the 3 rd water plant is mainly from the water in the reservoir area north of the pump house of the 2nd water plant. Under the southeast wind, the water intake area of the 2nd water plant is at the upper vent, and the upper water body the algae in the water are not easy to accumulate in the waters. This layout plan is conducive to the water supply of the Yangtze River water after it is uniformly mixed in the reservoir.

\section{SIMULATION OF RESERVOIR WATER EXCHANGE CYCLE}

Due to the poor fluidity of the water in the reservoir, the water exchange period of the water in the reservoir area is also different. In some areas, such as the hydration inlet area, the water exchange period is short, while the longer area has a longer water exchange period. In order to understand the difference of the water exchange 
period of the Taicang Liu River Reservoir in different pumping stations in the 2nd water plant, the EFDC model developed by the US Environmental Protection Agency was used to simulate the summer water life cycle under the current conditions. The calculation analysis makes the following assumptions:

(1) Long-term exposure to SE wind or SSE to wind, wind speed $3.6 \mathrm{~m} / \mathrm{s}$;

(2) The initial operation water level of the reservoir is $0 \mathrm{~m}$, the flow of the Yangtze River supplementary reservoir is $33.5 \mathrm{~m}^{3} / \mathrm{s}$, and the water supply from the reservoir is added to the water of the Yangtze River, and the Yangtze River water is stopped after 1.5 days;

(3) The water supply flow rate of the reservoir is 400,000 tons/day, and the water supply of the 2 nd water plant and the 3 rd water plant is 200,000 tons/day;

(4) Replenish the Yangtze River once every 10 days, and the duration of each replenishment is 1.5 days.

Through numerical simulation, the distribution map of the water exchange period in the reservoir area as shown in Figure 4 is obtained.

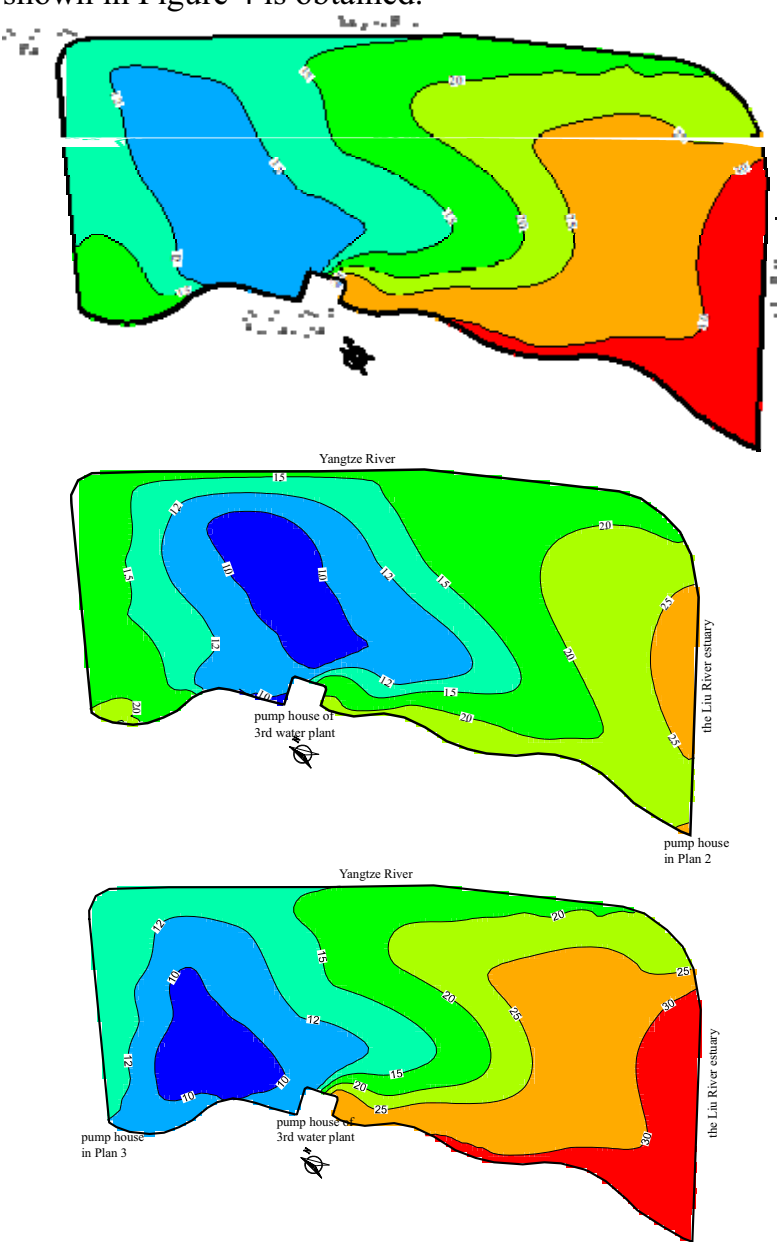

Fig. 4 distribution of water cycle in reservoir area under SE wind $3.6 \mathrm{~m} / \mathrm{s}$ (unit: day)

The average water exchange period of the reservoir and the water exchange period of the water intake are shown in Table 1.

Table 1 Statistical Table of Average Water Change Period of Reservoir and Water Change Period of Water Intake (Unit: Day)

Layout plan

Average water

water exchange perio

water exchange

\begin{tabular}{cccc}
\hline $\begin{array}{c}\text { exchange period in the } \\
\text { reservoir area }\end{array}$ & $\begin{array}{c}\text { of 2nd water plant } \\
\text { water intake area }\end{array}$ & $\begin{array}{c}\text { period of 3rd } \\
\text { water plant water } \\
\text { intake area }\end{array}$ \\
\hline 1 & 20.0 & 13.5 & 11.9 \\
2 & 16.3 & 23.2 & 10.1 \\
3 & 20.4 & 11.8 & 11.9 \\
\hline
\end{tabular}

The calculation results above show that:

(1) The pumping room layout plan 2 of the 2 nd water plant is conducive to the full mixing of the reservoir Yangtze River supplementary water and the reservoir water. The average water exchange period in the reservoir area is shortened from the 20 days of the layout plan 1 and plan 3 to 17 days; the plan 1 and the plan 3 these two layout plans have little impact on the overall water exchange cycle of the reservoir and the water exchange period in the south reservoir area of the $3 \mathrm{rd}$ water plant pumping house, but have a greater impact on the water exchange period in the reservoir area north of the 3rd water plant, which mainly shows a large difference in the distribution of short water exchange periods less than 12 days.

(2) The pump house of the 2 nd water plant adopts layout plan 1 and plan 3 to form a large area of difficult water change period in the southern waters of the reservoir. The area with a water change period of more than 25 days will reach an area of about $1 / 4$ of the reservoir area. The layout plan 2 can greatly reduce the water exchange period in the southern waters of the reservoir. Compared with the first and second plans, the water exchange period in the southern waters can be shortened by 5 days.

(3) Under the southeast wind conditions, the overall water exchange period of the reservoir is slightly shorter than that of the southeasterly southerly wind, indicating that the southeast wind is more conducive to the full blending of the Yangtze River supplemental water in the reservoir.

(4) From the perspective of water change cycle, the advantages and disadvantages of plan 1 and Plan 3 are equivalent, while plan 2 is obviously superior to plan 1 and plan 3 .

(5) Although the average water exchange period of the water intake area of the 2 nd water plant is at 23 days, the algae in the upper water body are not easy to accumulate in the water intake due to the upper wind inlet in the summer. In terms of layout plan 2 , it is also beneficial to improve the water quality of the 2 nd water plant.

\section{OPTIMAL ANALYSIS OF WATER INTAKE LOCATION}

As the current 3rd water plant pumping station is located in the middle of the west side of the Liu River, there are three main options for the site selection of the new pumping station. Plan 1: The site of the pumping station is located at the northeast corner of Liu River Reservoir; Plan 2: The site of the pumping station is located at the southwest corner of Liu River Reservoir; Plan 3: The site of the pumping station is located at the northwest corner of Liu River Reservoir. 
The following summarizes the advantages and disadvantages of the three plans from the perspective of hydraulics.

(1) Under the prevailing wind conditions in summer, no matter which layout plan is adopted, the flow direction of the surface water of the reservoir flows from the south to the north. The second plan is arranged in the upper wind of the Liu River Reservoir in the prevailing wind, and the cyanobacteria of the upper water body is not easy to gather in the waters of the water.

(2) When the pump house of the 2 nd water plant is arranged at the northeast or northwest corner of the Liu River Reservoir, the water is mainly from the water in the northeast corner of the reservoir area and the reservoir in the eastern half. This part of the water body is basically the newly replenished Yangtze River water, and the 3rd water plant water intake mainly comes from the water body of the western half of the reservoir near the pump house. As a result, the water in the southwest corner of the reservoir is difficult to get mixed with the newly replenished Yangtze River water, causing a large amount of new water to be removed and a large amount of old water not being mixed with new water. When the pumping room is arranged in the southwest corner of Liu River Reservoir, the water intake of the 2 nd water plant is mainly from the water reservoir in the south of the pump house of 3 rd water plant. The water intake of the 3rd water plant is mainly from the north of the pump house of 3rd water plant. The water is conducive to the water supply of the Yangtze River in the reservoir after mixing as a whole. The average water exchange period in the reservoir area is shortened from 20 days to 17 days in the first plan.

(3) When the pump house of the 2 nd water plant is arranged at the northeast corner or the northwest corner of the Liu River Reservoir, the advantage is that the water intake water is close to the supplementary water outlet, and the water exchange period is 13 days; when the water intake head of the 2 nd water plant occurs, the algal bloom occurs. Immediately fill the Yangtze River water, the Yangtze River water only needs to reach the water source of the 2 nd water plant after 2 days; the pump discharges water to the Yangtze River through the dark pipe, which has less environment impact; the disadvantage is that the water intake is in the downwind, which is not conducive to shortening the reservoir area. During the overall water change cycle, there is a water change dead angle in the southwest corner of the reservoir, and the water change period is greater than 30 days.

(4) When the pump house of the 2 nd water plant is arranged in the southwest corner of the Liu River Reservoir, the advantage is precisely the shortcoming placed in the northeast corner. The disadvantage is that the water exchange period of the water intake period is longer, reaching 23 days. The Yangtze River can affect the water intake water 5 to 6 days after the water is replenished to the reservoir. However, due to the upper wind inlet in the summer, the algae in the upper water body are not easy to accumulate in the water intake. In general, the layout plan 2 is also conducive to improving the water quality of the 2 nd water plant.
(5) When the 2nd water plant adopts the layout plan 2 , the effect of adding water pump is obvious. However, when the layout plan 1 and plan 3 are used, the water pumping effect on the water change period in the southern waters is not obvious. When the 2 nd water plant adopts the layout plan 2 , and the flow rate of the pump is increased to $1.7 \mathrm{~m}^{3} / \mathrm{s}$ (that is, $150,000 \mathrm{~m}^{3} /$ day), the average water exchange period in the reservoir area is shortened from 17 days to 12 days under the prevailing wind conditions in summer. The water change cycle in the southern waters will be shortened to 13 days. Considering that the summer wind direction is unlikely to be a constant wind direction, the actual water exchange period in the southern waters is shorter than the calculation result. Therefore, when the pump flow rate reaches $150,000 \mathrm{~m}^{3} /$ day, the water exchange period of the reservoir area can be basically less than 15 days. When adopting the layout plan 1 and plan 3 , it is uneconomical to add a water pump to continue operation in a special period in summer to shorten the water exchange period in the reservoir area. It is recommended to suppress the water bloom by emergency supplementing the Yangtze River when cyanobacteria occur. Then, the machine is operated to the dead water level. The 3rd water plant uses the Yangtze River water to continue the water supply. The 2 nd water plant stops the water supply and uses the emptying pump to drain the reservoir to completely change the water.

In summary, from the perspective of hydraulics such as circulation and water exchange period in the reservoir area, the layout plan of the pump house of 2 nd water plant is located in the southwest corner of Liu River reservoir, which is obviously superior to plan 1 and plan 3 , while plan 1 and plan 3 are difficult to distinguish.

\section{CONCLUSION}

Natural conditions such as nitrogen and phosphorus nutrient input, water depth and temperature of the reservoir are difficult to control. By optimizing the location of the pumping house, the circulation characteristics of the reservoir can be changed, the water exchange cycle can be improved, and the growth of cyanobacteria can be suppressed by the Yangtze River water, thereby reducing the eutrophication of the reservoir. Risk is a measure of objective reality.

\section{References}

1. Hejzlar, J. (2006) Management options to control ecological potential of reservoirs, Proc. The 5th Interntl. Conf. Reservoir Limnology and Water Quality, August 27-31, 2006, Brno, Czech Republic, Institute of Botany of the Czech Academy of Sciences. Schindler DW. 2006. Recent advances in the understanding and management of eutrophication. Limnol Oceanogr. 51:356-363.

2. 2.LI Y P, ACHARYA K, CHEN D, et al. Modeling water ages and thermal structure of Lake Mead under changing water levels[J]. Lake and Reservoir Management,2010,26: 258-272. 
3. 3.LI Y P, ACHARYA K, YU Z B. Modeling impacts of Yangtze River water transfer on water ages in Lake Taihu, China $[\mathrm{J}]$. Ecological Engineering,2011, 37( 2) : 325-334 .

4. Shao Junrong, Wu Shiqiang, Zhou Jie et al. [J]. Advances in Water Science, Volume 25, No. 5, 2014:695-703. 